\title{
An Environmental Control System for ALS Patient Using Finger Movement
}

\author{
Chao Zhang1, Masatomo Shibata1, Keisuke Takashima1', Jiangli Yu¹, Takakazu Ishimatsu1, \\ Joel Palomino ${ }^{2}$ \\ ${ }^{1}$ Nagasaki University Graduate School of Engineering, Nagasaki University, Nagasaki, Japan \\ ${ }^{2}$ Pontificia Universidad Catolica del Peru \\ Email: bb52311103@cc.nagasaki-u.ac.jp, m-shibata@zeshinkai.or.jp,k-yakashima@nagasaki-u.ac.jp, \\ bb52213182@cc.nagasaki-u.ac.jp, ishi@nagasaki-u.ac.jp
}

Received 24 September 2015; accepted 8 November 2015; published 11 November 2015

Copyright @ 2015 by authors and Scientific Research Publishing Inc.

This work is licensed under the Creative Commons Attribution International License (CC BY).

http://creativecommons.org/licenses/by/4.0/

(c) (i) Open Access

\begin{abstract}
ALS is a degenerative disease which affects the patients muscular activity in feet and hands, leading to a bed ridden status. The loss of independency affects their will to live, for this reason an environmental control system to handle the home appliances and make telephone calls is proposed. The system uses a tablet as a visual human interface so that the patient can select the desired appliance by selecting the corresponding item on the tablet screen. Based on the remaining patient's abilities an input device that detects slight finger movement is proposed. In this paper three types of input devices are considered and their performance is evaluated by four ALS patients. Their comments about the usage of the devices are discussed in this work. Finally the environmental control was implemented on an ALS patient home and their impressions were satisfactory for the patients, relatives and care-givers.
\end{abstract}

\section{Keywords}

Environmental Control, ALS patient, Input Device, Touch Sensor, Pressure Sensor

\section{Introduction}

Amyotrophic lateral sclerosis (ALS) is a well-known disease because of the worldwide ice bucket challenge. The challenge highlights the needs to continue the research and social supports for ALS patient. In Japan around 8000 people have this disease and 30,000 in the USA. The ALS is a progressive and devastating neurodegenerative disease, which affects motoneurons in the cerebral cortex, brainstem and spinal cord, leading to paralysis and death [1]. 
Patients who suffer from ALS require constant attention from a nurse. A typical ALS patient can be observed in Figure 1, where all his intentional muscular abilities are limited only to slight head movements, fingers movements and eye movements. It may happen that in less than a year his breathing ability will deteriorate and will need an artificial respirator. Until now patients' daily lives are dependent on family and care-givers. Therefore, relationships of the ALS patients with society are extremely limited.

In order to assist their daily lives and give them more independency, scientific technologies were introduced. Communication devices were developed to substitute patient's vocal communication by using sensors and computers [2]. For example, communication devices that use acceleration sensors and also image processing were developed for ALS patient [3]. Also environmental control systems to enable the patient to control electric appliances were developed [4]. Due to these developments, every ALS patient with serious physical disabilities could enjoy the TV and Internet using his remaining physical abilities by himself [5]. As everyone notices the scientific technologies are developing, therefore devices to assist ALS patients should be developed [6]. One remarkable development in our lives is the mobile devices which are widely used in various fields. Communication using compact touch pads and mobile phones is available in every place and anytime. These mobile devices have various potential abilities in the field of assisting devices for patient with serious disabilities like ALS patient [7].

In this paper an environmental control system using an android tablet is proposed. A distinguished feature of the system is that the tablet and controlled devices are connected wirelessly. Therefore, the system could be compact and available under various nursing environment. Also various input devices operated by slight finger movement are focused on in this paper. Already various input devices were proposed based on image sensor, acceleration sensor, touch sensor and so on. An important aspect of the input device is that it should be introduced based on the patient physical condition. The devices proposed in this paper are designed to be comfortable, stable and wearable. Applicability of the tablet system and the input devices are evaluated by ALS patients.

\section{Configuration of Environmental Control System}

The proposed control system that employs the tablet as a main controller is shown in Figure 2. The tablet is connected to two controllers via Bluetooth. The first one is an input controller, which receives the signal from the input device. The second one is an infrared controller for the home appliances such as Room-light, TV, Airconditioner and so on. It should be noticed that the infrared controller includes an original bed remote controller. Additionally the tablet is connected to the telephone network, so the patient can make phone calls to his relatives or the hospital. The user is supposed to operate the tablet by using his slight finger movements.

In the following sections each of these are explained in detail.

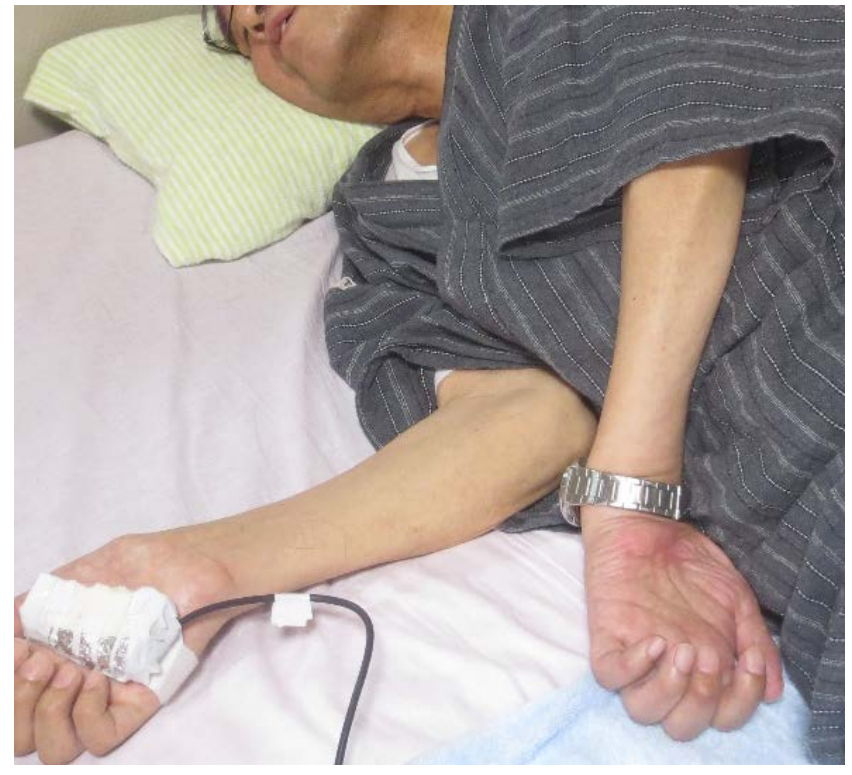

Figure 1. ALS patient. 


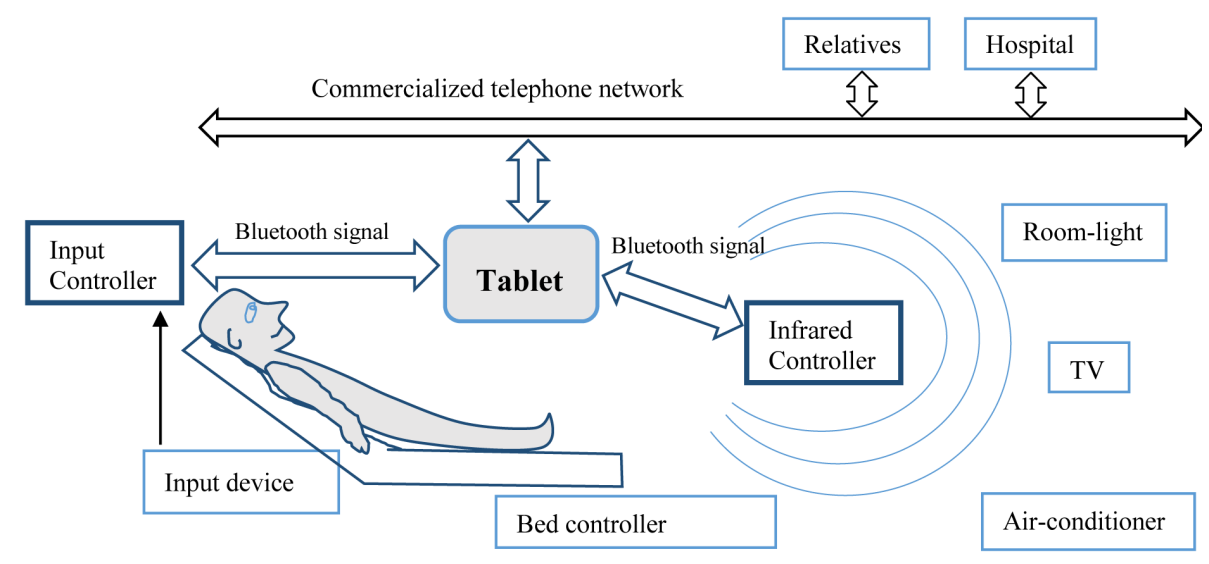

Figure 2. System configuration with wireless network.

\subsection{Tablet Computer}

The tablet main function is to serve as a visual interface for the ALS patient. In this tablet the developed android application program is executed, the application screen is shown in Figure 3. On the left side of the screen the main menu is listed, and on the right side, the sub-menu items are listed. The patient selects the desired menu or sub menu through an input device. Depending on the selected menu or sub menu the patient can make phone calls through the Wi-fi internet to relatives or hospital; or control the home appliances that have functions controlled by infrared signal. In addition to the home appliances, the tilt angle and height of the bed can be changed by the infrared controller.

The selection method is as follows:

On the tablet screen, menu item or sub-menu item is highlighted sequentially one by one.

In case, the desired menu item or sub-menu item is highlighted, the user activates the input device.

The desired menu item is selected and corresponding application program starts.

Relation between main menu and sub menu is explained in Figure 4.

\subsection{Input Controller and Input Device}

As a human interface for ALS patient input devices are essential to live independent and well life. In this paper, a slight finger movement is focused as effective input signals. The controller obtains the signal from input device and sends the data to tablet through Bluetooth. Figure 5 shows the input device controller.

In this paper input devices to detect slight finger movements of ALS patients are considered. In Figure 6 three types of input devices (touch switch, mouse switch and push button) are shown. This touch switch is activated by a slight touch of the human body using static electricity. Currently many of the ALS patients use these techniques.

In Figure 6(a) an ALS touches the tip of the sensor. Then, the output signal of the touch sensor is activated.

In Figure 6(b) an ALS patient clicks the mouse button with his index finger. A problem for him and the caregiver is that his fingers and the mouse need to be properly arranged with accuracy. This arrangement task is annoying for the care-giver.

In Figure 6(c), an ALS patient is pushing the button. Also the arrangement is an annoying task.

In addition, both ALS patients feel that pushing the click button is becoming hard. Therefore, care-givers are seeking for alternative methods.

Alternative devices to detect slight finger movement are considered and various types of input devices are designed considering the stable and reliable switching by the user and easy setup for the care-givers as shown in Figures 8-10.

In these devices, pressure sensor (Interlink Electronics model FSR 406) and touch sensor are used. In Figure 7 the pressure sensor and electrode of touch sensor which are used in our devices are shown.

Grip type input device (Figure 8)

A feature of the grip type input devices is its easiness to wear on the hand. The input devices (a), (b) use 


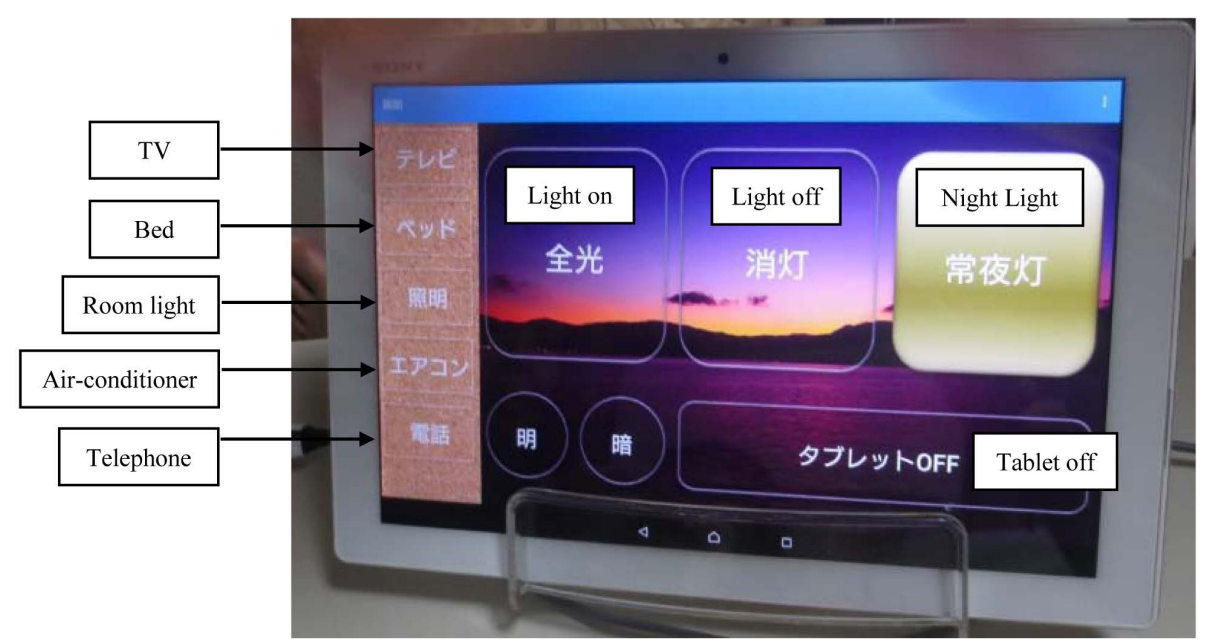

Figure 3. Application screen for supporting ALS patient.

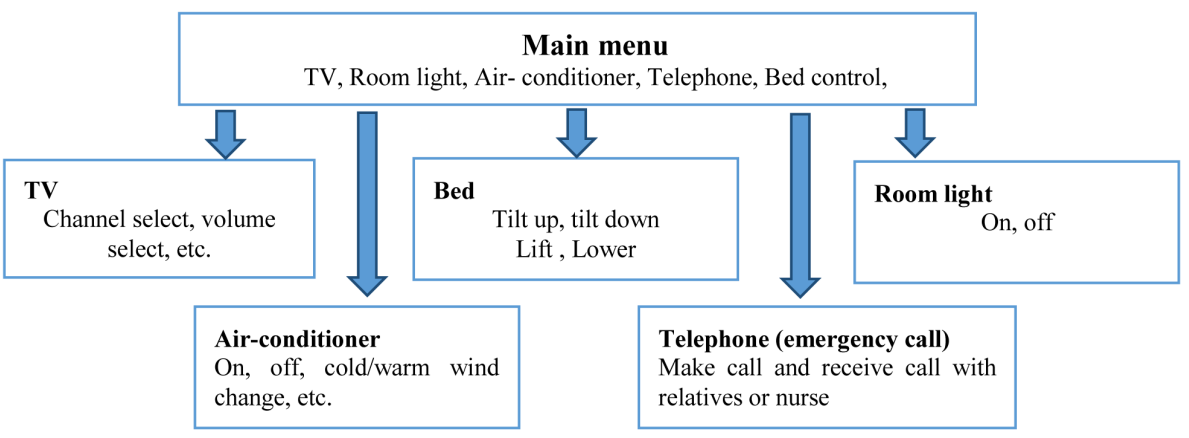

Figure 4. Relation between main menu and sub menu.

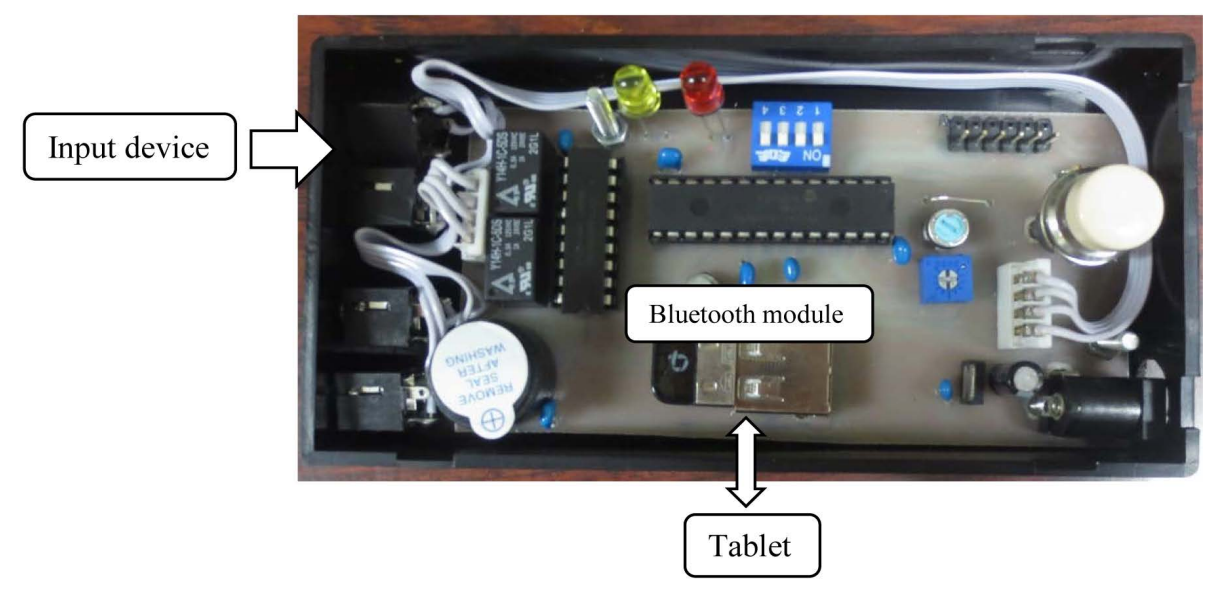

Figure 5. Developed input controller.

pressure sensors. The input device (a) has a simple bar-type. And the input device (b) is hand shaped so that this device can fit in the palm of the hand. The input device (c) uses touch sensor is activated by a slight touch of the fingers.

Box type input device

Figure 9 shows box type input device. The user locates his hand on the box type input device so the user can push or touch the sensor by his slight finger movement. The front side of the box pressure sensor or touch sensor should be settled based on the physical ability of the ALS patient. By shaping the box, the locating task can be 


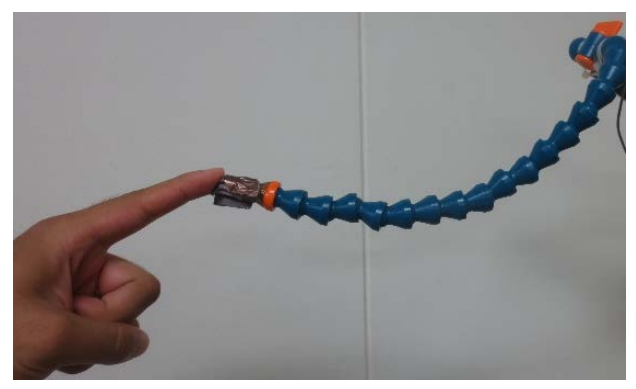

(a)

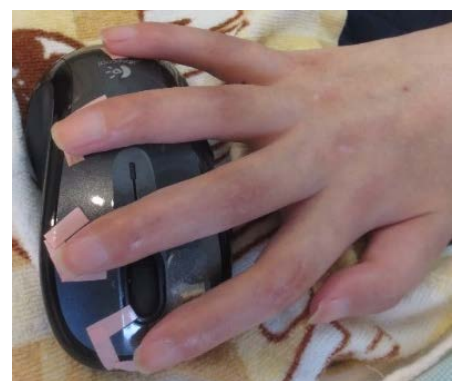

(b)

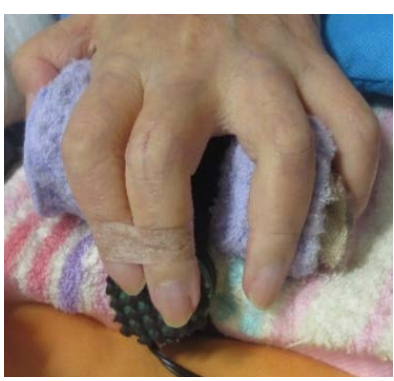

(c)

Figure 6. Current input methods for ALS patient. (a) Switch to use touch sensor; (b) Switch to use computer mouse; (c) Switch to use push button.

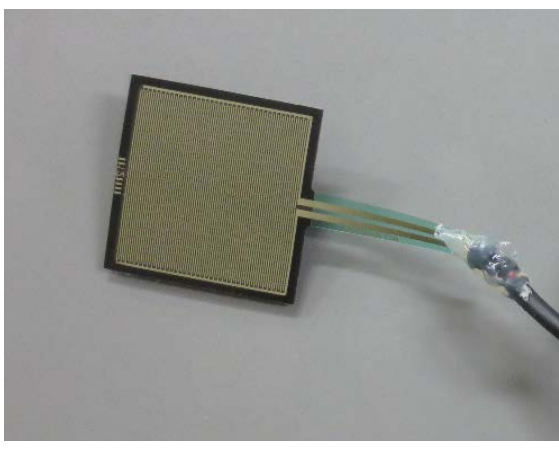

(a)

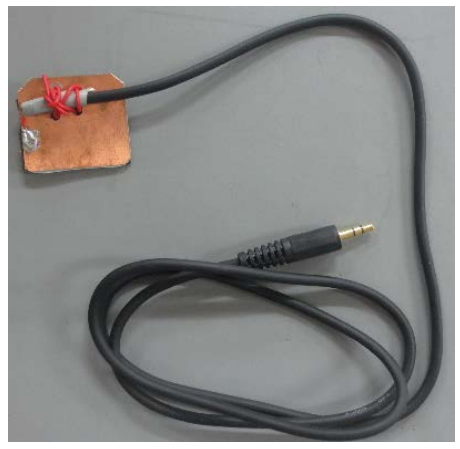

(b)

Figure 7. Two type sensors. (a) Pressure sensor; (b) Electrode of touch sensor.

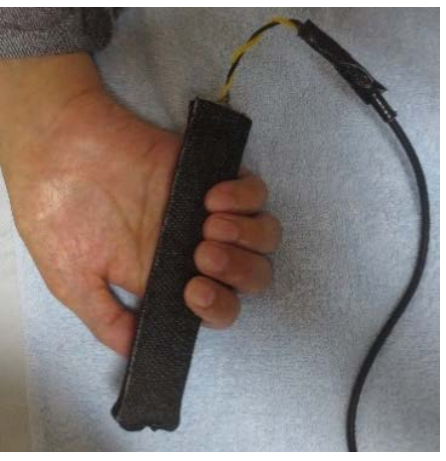

(a)

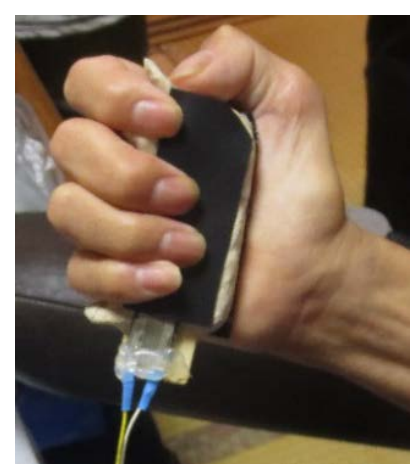

(b)

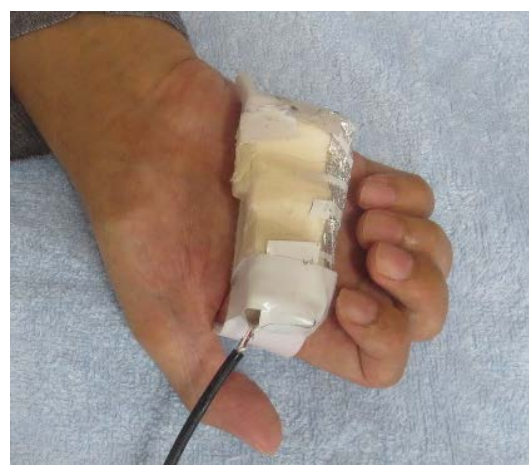

(c)

Figure 8. Grip type input device. (a) Grip type device1; (b) Grip type device 2; (c) Grip type device 3.

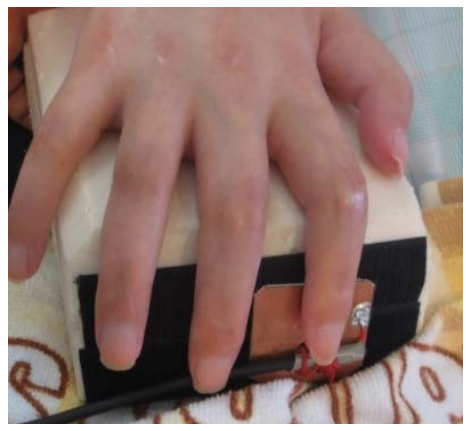

Figure 9. Box type input device. 
easier for the care-givers.

Sheet type input device

Figure 10 shows the sheet type input device. The pressure sensor is placed on the square board over a wide board. By introducing this convex shape, the user can feel the position of the sensor by his hand. A feature of this device is that the user doesn't need to wear it. The care-giver can move the sensor conveniently according to the user's hand position.

\subsection{Infrared Controller}

In order to control the home appliances, an Infrared controller is developed. This controller receives commands from the tablet through the Bluetooth and emits the corresponding infrared signal to the home appliance. The infrared controller is composed as shown in Figure 11. The infrared controller is available for various types of home appliances since the controller has the function to learn the signal from the remote controller. The acquired data are stored in EEP ROM on the microprocessor (PIC24).

In Figure 12, the photo of the infrared controller is shown. This controller employs ten infrared emitters.

\subsection{Bed Controller}

ALS patients often spend most of their time on the bed. They want change their body position and posture by themselves. The bed remote controller which is already prepared is difficult to operate by slight finger movement of ALS patients. Therefore a mechanical switching device is proposed as shown in Figure 13 and Figure 14.

Figure 13 shows the structure of the bed remote controller. The microprocessor (PIC24) receives the commands from the infrared controller and activates the corresponding relay switch. The relay switches physically push the corresponding lever on the remote controller through the solenoid as shown in Figure 14. In this figure,

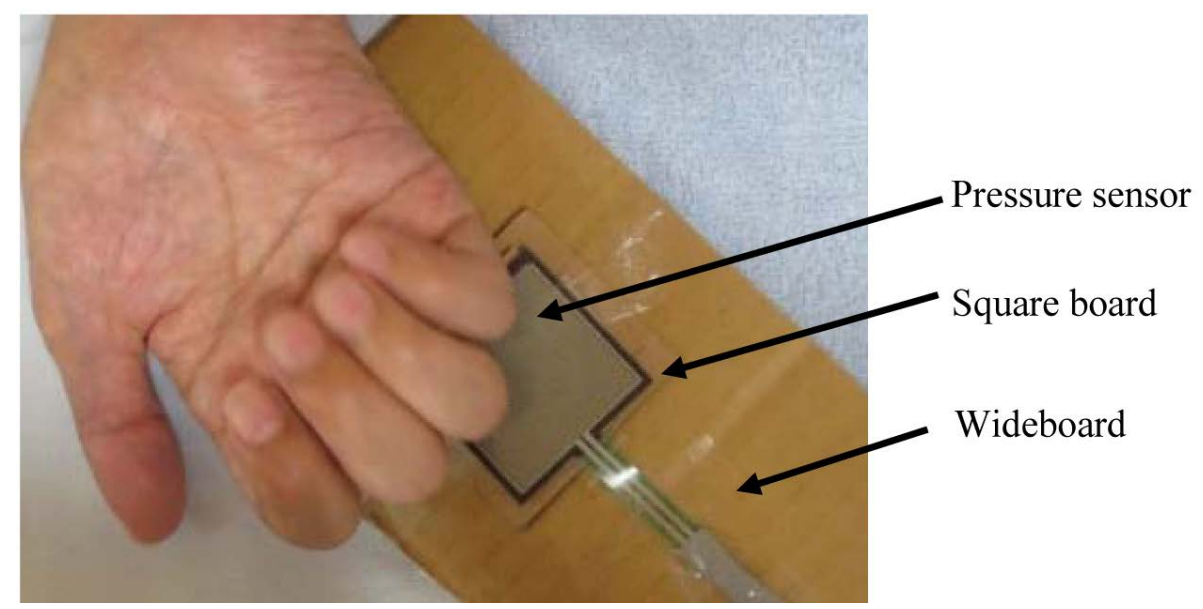

Figure 10. Sheet type input device.

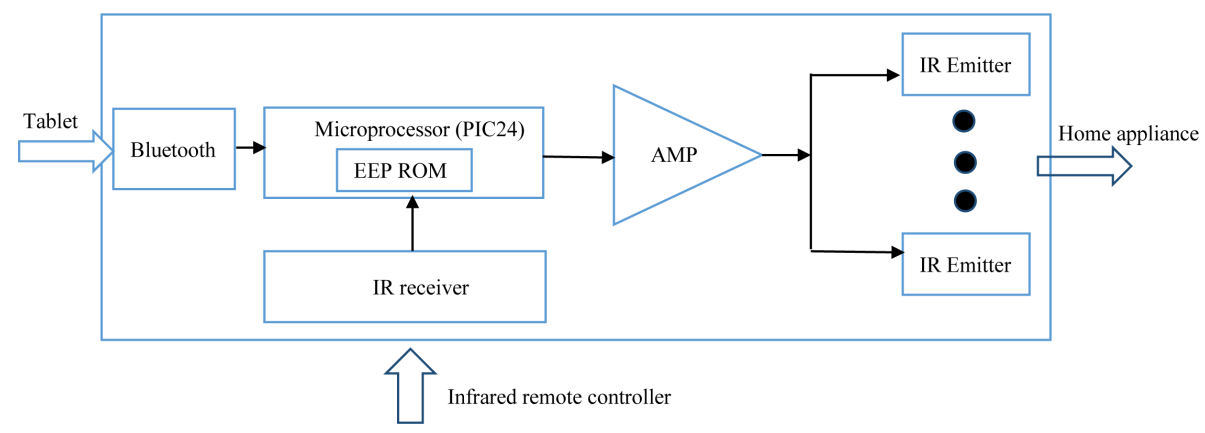

Figure 11. Developed infrared controller. 


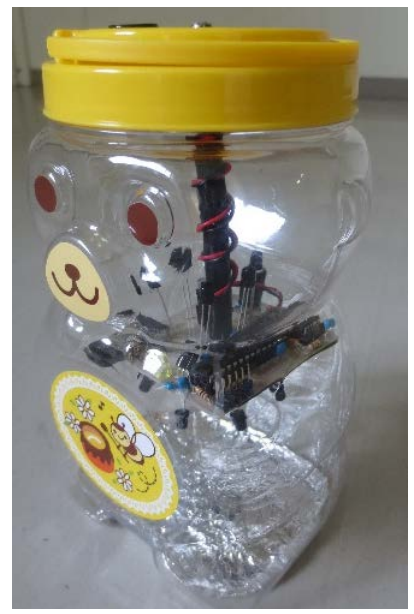

Figure 12. Developed infrared controller in a bear shape bottle.

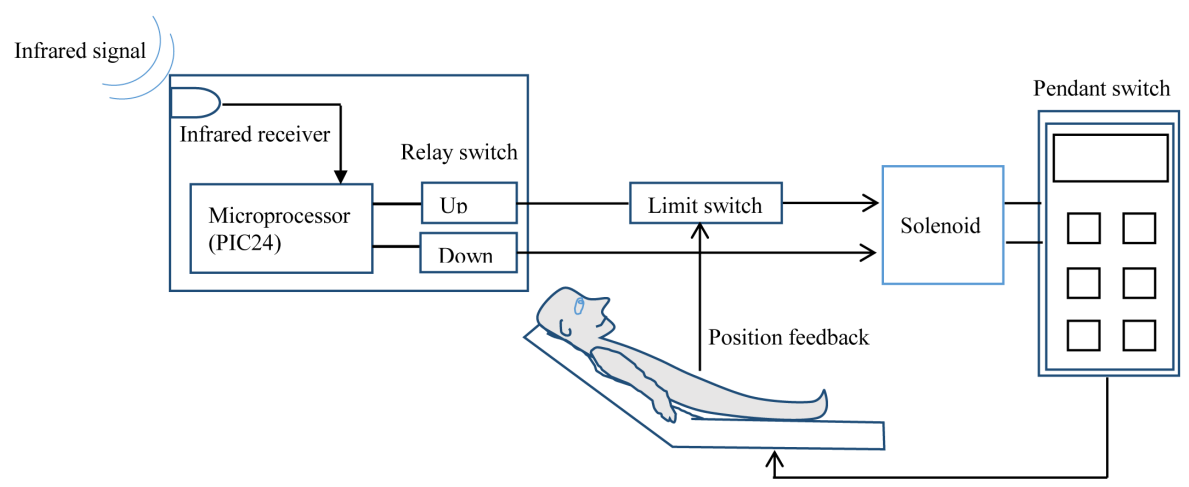

Figure 13. Bed controller.

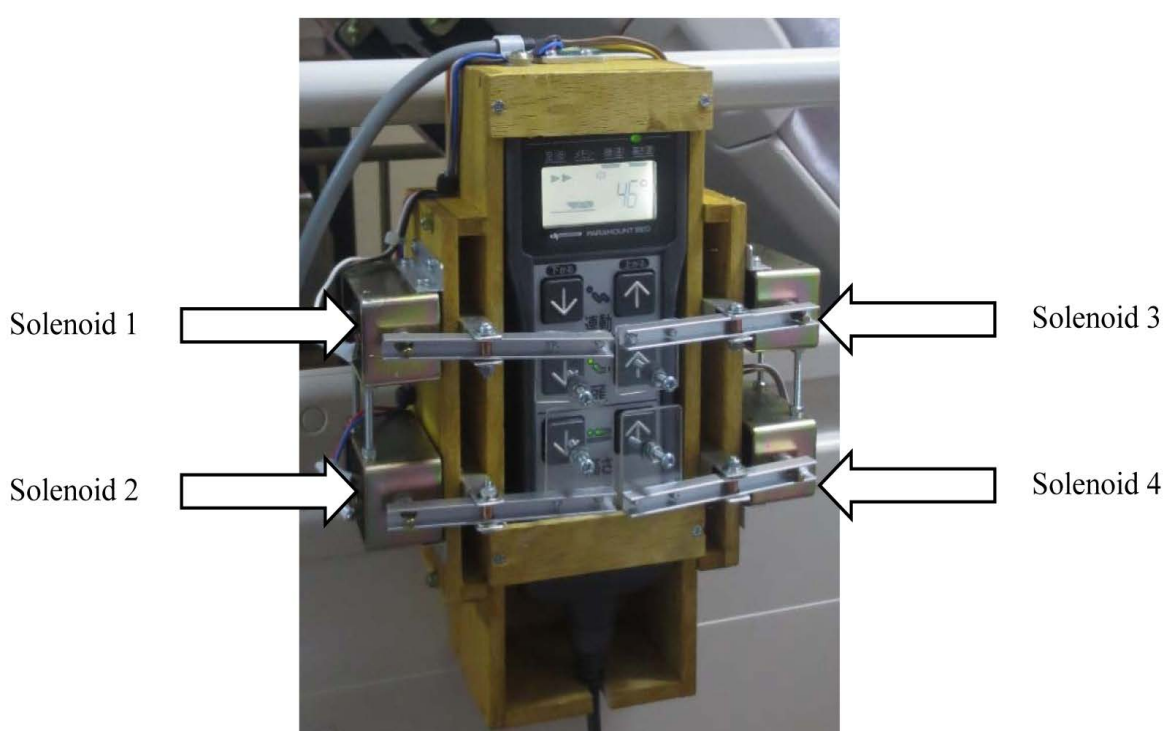

Figure 14. Pendant switch with solenoids.

four solenoids are mounted. Two solenoids control the tilt angle of the bed. And the other two solenoids change the height of the bed. For safety reasons, a limit switch is employed to limit the tilt angle of the bed up to 45 degree. 


\section{Evaluation by ALS Patient}

Four ALS patients evaluated the proposed input devices. All of them have difficulty for computer input task. Also adjustment of input device position is a problem for care-givers. In Table 1, patients' background, medical history and problems in their daily life are explained.

All of them were requested to evaluate the effectiveness of the proposed input devices. And the following comments were obtained.

- Comment about grip type input device:

Patients C could operate this input device without difficulty. Other patients could not operate this input device with stability.

But care giver said the setting task on the hand is easy. This input device is effective for certain kind of ALS patients.

- Comment about Sheet type input device

Patients A, B, C were satisfied with the usability of this input device. Comparing the two versions of this device one with the pressure sensor and the other with the touch sensor, the pressure sensor was friendlier since the touch sensor was too sensitive. Patient B was satisfied because wearing the sensor on the hand was annoying for him.

- Comment about box type input device

Patients A, C and D were satisfied with the functionality of this input device. Patient B could move his hand position on the bed but he could not lift his hand toan adequate position on the box. Therefore, he preferred the sheet type input device.

- Comment about input device with touch sensor

Input device with touch sensor had high sensitivity. Therefore, users don't require strength on the finger and hand. This feature was important for the patient with serious physical disabilities. Patients A and C in the near future will have difficulties to move the fingers. In that situation the touch will become handily for them.

- Comment about input device with pressure sensor

It is important to note that sensing abilities on the body and fingers remains in ALS patient. When people operated the switch, they wanted to feel the switch action. The input device with pressure sensor is less sensitive to the finger movement. This feature is preferable to the user since he can feel the position of the switch before activation. All patients were satisfied with this feature and especially patient B.

The proposed environmental control system to use tablet was tested by the ALS patient B for three weeks as shown in Figure 15. The patient uses the grip type input device to communicate with his family through a laptop which is connected to the tablet. He and his family were satisfied with its functionality. Especially they were impressed with the telephone function to call the nurse and also with the TV control functions. Due to these functions his wife was grateful with the system, and she could sleep soundly in the night.

Table 1. Information about ALS patients.

\begin{tabular}{|c|c|c|c|}
\hline Patient(age) & Medical history & Symptom & Conventional control methods and problem \\
\hline A(45 years old) & Diagnosed in 2010 & $\begin{array}{l}\text { His physical abilities are slight movements of } \\
\text { the index finger. The patient could not } \\
\text { pronounce a word. } \\
\text { The patient is under bed-ridden status. }\end{array}$ & $\begin{array}{l}\text { Patient uses the index finger to push the mouse } \\
\text { button for clicking (Figure 6(b)). Care givers have } \\
\text { difficulties to adjust the fingers and mouse } \\
\text { position adequately. }\end{array}$ \\
\hline B(64 years old) & Diagnosed in 2013 & $\begin{array}{l}\text { His physical abilities are right hand finger and } \\
\text { wrist movement. The patient could pronounce } \\
\text { words with some difficulty. }\end{array}$ & $\begin{array}{l}\text { Patient can use the mouse with some difficulty. } \\
\text { The patient symptom is becoming serious and } \\
\text { requires environmental control system and input } \\
\text { devices. }\end{array}$ \\
\hline C(48 years old) & Diagnosed in 2012 & $\begin{array}{c}\text { He can stand and walk with some difficulty. He } \\
\text { can move his hands slightly. The patient could } \\
\text { not pronounce a word. }\end{array}$ & $\begin{array}{l}\text { He operates a smart phone to communicate with } \\
\text { others using slight finger movements. But the } \\
\text { symptom is becoming serious. He requires an } \\
\text { input device for computer. }\end{array}$ \\
\hline D(72 years old $)$ & Diagnosed in 2009 & $\begin{array}{l}\text { The patient can move her finger slightly. The } \\
\text { patient could not pronounce a word. } \\
\text { The patient is under bed-ridden status. }\end{array}$ & $\begin{array}{l}\text { She uses the index and middle fingers to push the } \\
\text { button (Figure 6(c)). But the task requires lot of } \\
\text { concentration and physical strength. }\end{array}$ \\
\hline
\end{tabular}




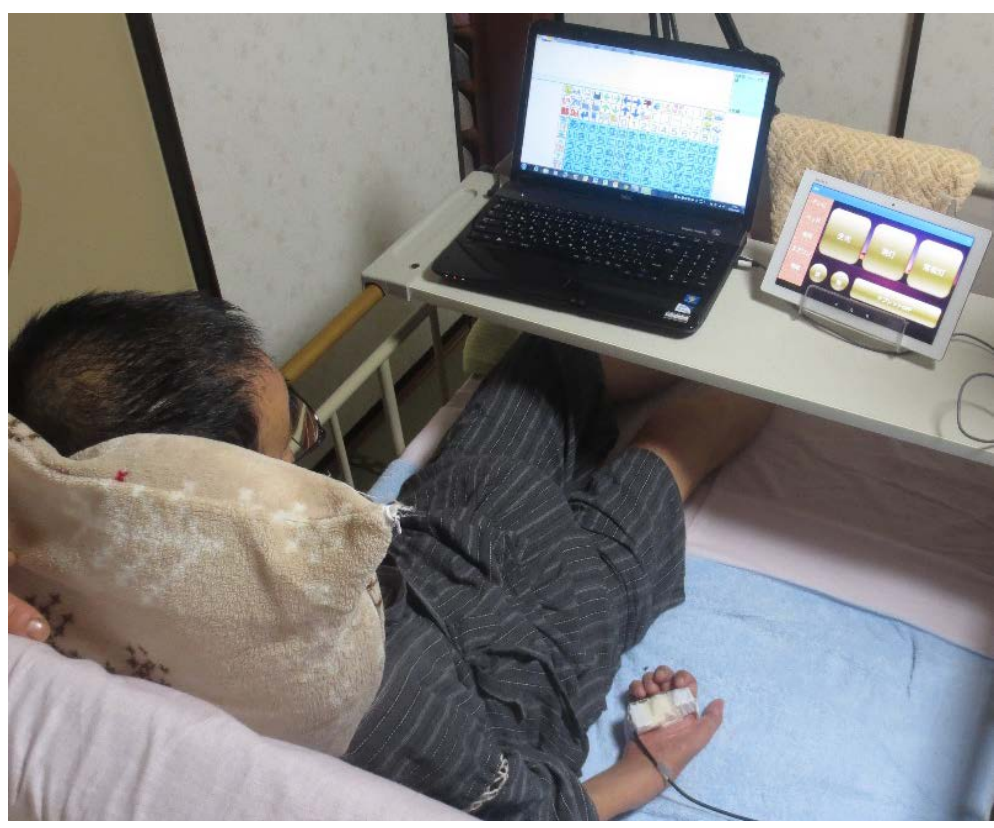

Figure 15. Implemented environmental control system in an ALS patient home.

\section{Conclusions}

An environmental control system using a tablet for ALS patients was developed and fully implemented for an ALS patient.

Three types of input devices were designed for ALS patient with slight finger movement. The input device was evaluated by four ALS patients on the standpoint of feasibility, sensibility and reliability. As a result of the input device evaluation, the sheet type input device with pressure was highly preferred by the ALS patients and care-givers.

Application of the input device to the ALS patient always requires skills and experiences. Due to the proposed devices using wire-less communication, patients and care-givers praised its usability..

The test in ALS patients was done to understand the weak and strong points of each device when used by the patients. The sheet type device was found to be superior over the others devices.

In the other cases, according to care-givers, the box type and grip type device have a potential to be superior devices for other patients.

The original bed control device proposed in this paper helps the ALS patient to regain independency in his life since he needn't depend on a nurse to change his body position.

The applicability of the environmental control system using the tablet was tested for three weeks. The family was impressed by the functionality and applicability of the system.

\section{References}

[1] Gonzalez-Perez, P., Woehlbier, U., Chian, R.-J., Sapp, P., Rouleau, G.A., Leblond, C.S., et al. (2015) Identification of Rare Protein Disulfide Isomerase Gene Variants in Amyotrophic Lateral Sclerosis Patients. Gene, 566, 158-165.

[2] Zhang, C., Ishimatsu, T., Yu, J., Lawn, M. and Shi, L. (2015) Vision-Based Displacement Sensor for People with Serious Spinal Cord Injury. The 2015 IEEE International Conference on Mechatronics and Automation (ICMA 2015), Beijing, 2-5 August 2015, 772-777.

[3] Takami, O., Morimoto, K., Ochiai, T. and Ishimatsu, T. (1995) Computer Interface to Use Head and Eyeball Movement for Handicapped People. 1995 IEEE International Conference of System, Man and Cybernetics, Vancouver, 22-25 October 1995, 1119-1123.

[4] Yu, J., Zhang, C., Shiraishi, N., Ishimatsu, T., Lawn, M. and Tanaka, M. (2015) Pillow-Type Computer Input Device for Serious Spinal Cord Injury. Journal of Modern Mechanical Engineering, 5, 61-68. 
[5] Arai, K. and Yajima, K. (2008) Communication Aid with Human Eyes Only. IEEJ Transactions on Electronics, Information and Systems, 128, 1679-1686. http://dx.doi.org/10.1541/ieejeiss.128.1679

[6] Mizuta, M., Moromugi, S. and Ishimatsu, T. (2010) Measuring of Number-of-Chewing using Flexible Capacitive Sensor. Proceedings of 4th Asia International Symposium on Mechatronics, Vol. TP2-A-5-P221 in CD-ROM.

[7] Arai, K. and Yajima, K. (2010) Computer Input with Human Eyes Only Using Two Purkinje Images Which Works in a Real Time Basis Without Calibration. International Journal of Human Computer Interaction, 1, 71-82. 